\title{
Modern wood windows now and trends after the year 2020
}

\author{
Milan Palko ${ }^{1, *}$, Adela Palková1, and Peter Buday ${ }^{1}$ \\ ${ }^{1}$ Department of Building Constructions, Slovak University of Technology in Bratislava, Faculty of \\ Civil Engineering, Radlinského 11, 81005 Bratislava, Slovakia
}

\begin{abstract}
The article deals with the issues of wood windows applicable according to the expected requirements after the year 2020. It analyses the potential of the current top windows in regard to modern design, functionality, and building physical properties. By applying progressive material solutions, it is possible to create windows with proportionally variable frame solutions or even with frameless wing construction. The introduction of vacuum glass systems requires the optimization of the profile system of a wooden window. Modern quality glass systems bring the problem of condensation of water vapour on the exterior surface of the glass. Also, a new phenomenon in the emerging trend of energy-saving buildings and despite the use of quality wooden profile systems is the condensation of water vapour that occurs in the functional joint of the profile system of the wooden window. This fact is increasingly leading to mold growth in functional joints, which subsequently has a negative impact on human health.
\end{abstract}

\section{Windows requirements after 2020}

Directive 2010/31/EU of the European Parliament and of the Council on the energy performance of buildings lays down new requirements for the energy performance of buildings, defining as well the intended use of energy. This directive was implemented in the Slovak Republic with an amendment to Act No 300/2012 on the energy performance of buildings and amending Act No 555/2005 on the energy performance of buildings and amending certain acts, which amended Act No 50/1976 on urban and regional planning and the building code. The amended act came into force on 1 January 2013. Implementing Decree No 311/2009 of the Ministry of Construction and Regional Development of the Slovak Republic was superseded in its entirety by Implementing Decree No 364/2012 of the Ministry Transport, Construction and Regional Development of the Slovak Republic of 12 November 2012, which implements Act No 555/2005 on the energy performance of buildings and amending certain acts.

The motto of the recast EU directive is the objective of reducing energy consumption by $20 \%$ and greenhouse gas emissions by $20 \%$ over 1990 levels by the year 2020, and increasing the share of energy from renewable sources to $20 \%$. The directive defines

\footnotetext{
${ }^{*}$ Corresponding author: milan.palko@stuba.sk
} 
various measures through which these objectives will be achieved. In addition to the availability of various forms of energy and its efficient use, the directive also deals with positive environmental influences. The reduction in energy consumption, achieved as a secondary effect of the implementation of the requirements in the operation and management of buildings, should lead to a reduction of adverse influences on the environment.

Some of the requirements on building components arising out of the directive and the act are interpreted in Slovak Technical Standard 73 0540-2:2012 'Thermal Protection of Buildings. Thermal Performance of Buildings and Components. Part 2: Functional Requirements'. Requirements for windows are expressed using the heat transfer coefficient ' $U_{\mathrm{w}}$ ', with a maximum recommended value after 2020 of $\mathrm{U}_{\mathrm{w}} \leq 0.6 \mathrm{~W} /\left(\mathrm{m}^{2} . \mathrm{K}\right)$ for windows and exterior doors, and $\mathrm{U}_{\mathrm{w}} \leq 1.0 \mathrm{~W} /\left(\mathrm{m}^{2} . \mathrm{K}\right)$ for roof windows, measured or calculated in vertical position. Public buildings must comply with these numbers starting in 2018 [1-5].

\section{Profile solutions}

Wood-only window frames offer limited possibilities in terms of the requirements on thermal properties. Although a window profile built primarily of can be resolved by increasing the geometric proportions, this does not provide a good solution. A profile solution that is still optimal whilst being wood-dominant is shown in figure 1 (lower right). The insulation properties of the profile are improved with the use of air cavities that have better thermal characteristics than wood. The type of wood selected also plays an important role, as soft woods have better thermal properties than hard woods.
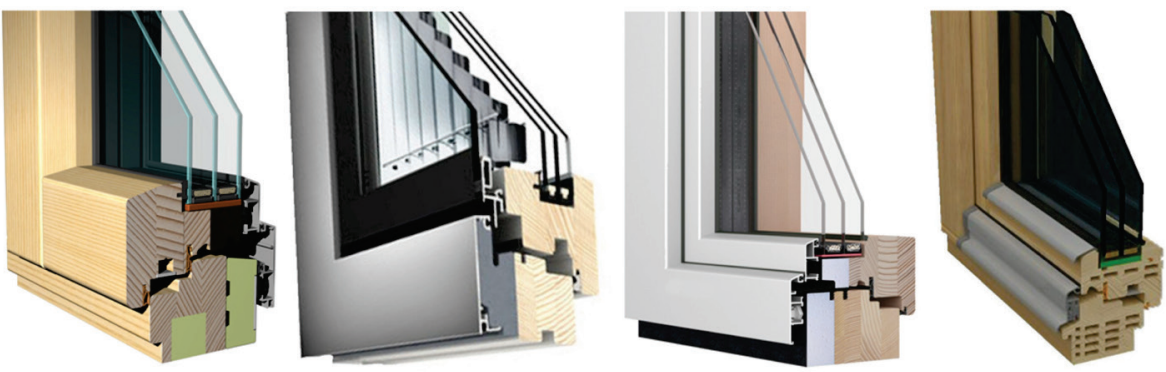

Fig. 1. Current top windows with $\mathrm{U}_{\mathrm{f}}=0,7-0,8 \mathrm{~W} / \mathrm{m}^{2} . \mathrm{K}$.

In some cases the insulation properties of specific types of wood are also affected by the location where the timber grows (varying thicknesses of summer and winter wood). The other examples in figure 1 are a combination of three wood-based materials, effective thermal insulant, and exterior aluminium portion. There are of course profile solutions containing plastic elements [3-5].

\section{Glass systems}

Advancements in glazing have focussed not only on glass and glass combinations and lowemissivity coatings. Modern technology makes it possible to achieve better glass property values such as thermal insulation, daylight transmittance, sound insulation, and others. A problem arises, however, when attempting to combine all the positive properties into one whole, as some of these properties are mutually exclusive. Research and development has begun to focus on dynamic glazing, where the glazing parameters can be set according to the actual season or the usage of a building (switchable glazing, shading systems, etc.). In 
today's market, glazing is available with values of $\mathrm{U}_{\mathrm{g}}=0.4$ to $0.6 \mathrm{~W} /\left(\mathrm{m}^{2} . \mathrm{K}\right)$ for triple glazing with argon or krypton filling.

For thermal properties in products of the highest category, we currently use insulated triple glazing with 4 layers of low-E coating and krypton cavity filling. We are starting to see the first applications of thermal quadruple glazing. The disadvantage of this option is its weight, which makes it difficult to use in the parts of the window that open. Vacuuminsulated glass is the more logical choice, but is not typically available at the moment. Theoretically, it can achieve a $U_{g}$ heat transfer coefficient of $0.15 \mathrm{~W} /\left(\mathrm{m}^{2} \mathrm{~K}\right)$ in vacuuminsulated double glazing. For vacuum-insulated triple glazing with four low-E coatings (emissivity of 0.05 ), the $U_{g}$ value would be less than $0.01 \mathrm{~W} /\left(\mathrm{m}^{2} \cdot \mathrm{K}\right)$. It should be added that the space between the panes would only be a few tenths of a millimetre wider, so the resulting thickness would be within the range of that used today in insulated glass. To eliminate heat conduction in the gas-filled space, there should be a vacuum with a value of $10^{-4} \mathrm{Bar}$ in the space between the panes, and this vacuum must be maintained for the entire life of the vacuum-insulated glass. This means extreme requirements on the air tightness of the special articulation of the edges of the panes. The load of the vacuum on the panes is approximately 10 tonnes per square metre. The pressure must be tamed using small spacers in the cavity between panes, but this increases thermal losses and can affect the transparency of the panes [3-6].

\section{Design and functionality}

There is a demand on modern windows to reduce the visibility of the frame and profile. Contemporary architecture prefers large glass panes without dividers. Likewise, the operational parts and fittings are integrated into profile systems to obtain maximum invisibility. Many of these demands are mutually incompatible in terms of the visualphysical-functional aspects.

\section{Potential of segments for heat transfer coefficient}

The heat transfer coefficient of window construction can be determined by the following ways:

- Measurement in big climatic chamber (method of enclosed hot chamber),

- Calculation (e.g. according to STN EN ISO 10077-1),

- Detailed computer simulation (analogically as by climatic chamber, but using computer model).

Using the enclosed hot chamber the steady temperature conditions is created, in order to describe transparent product having concrete dimensions based on formula (1):

$$
U_{w}=\frac{\Phi}{A\left(\theta_{i}-\theta_{e}\right)}
$$

Where $U_{w}$ is heat transfer coefficient of window $\left(\mathrm{W} /\left(\mathrm{m}^{2} . \mathrm{K}\right)\right)$, $\Phi$ is heat flow rate $(\mathrm{W}), A$ is area $\left(\mathrm{m}^{2}\right), \theta_{i}, \theta_{\mathrm{e}}$ is indoor and outdoor design temperature $\left({ }^{\circ} \mathrm{C}\right)$.

The new approach towards the quantification of thermal characteristics of opening constructions used in European standards included in the Slovak technical standards system (e.g. STN EN ISO 10077-1 Thermal characteristics of windows, doors and shutters. Calculation of heat transfer coefficient) enable designers to show the value of heat transfer coefficient for each window construction based on the values declared by an accredited company using the following formula: 


$$
U_{w}=\frac{U_{f} A_{f}+U_{g} A_{g}+\Psi_{g} l_{g}}{A_{g}+A_{f}}
$$

Where $U_{w}$ is heat transfer coefficient of window $\left(\mathrm{W} /\left(\mathrm{m}^{2} . \mathrm{K}\right)\right), U_{f}$ is heat transfer coefficient of frame $\left(\mathrm{W} /\left(\mathrm{m}^{2} . \mathrm{K}\right)\right), U_{g}$ is heat transfer coefficient of glass $\left(\mathrm{W} /\left(\mathrm{m}^{2} . \mathrm{K}\right)\right), \Psi_{\mathrm{g}}$ is linear thermal transmittance $(\mathrm{W} /(\mathrm{m} . \mathrm{K})), l_{g}$ is perimeter of glass $(\mathrm{m}), A_{f}$ is area of frame $\left(\mathrm{m}^{2}\right), A_{g}$ is area of glass $\left(\mathrm{m}^{2}\right)$.

The profile solutions and pane systems regularly available on the market cannot achieve the value of $U_{\mathrm{w}} \leq 0.6 \mathrm{~W} /\left(\mathrm{m}^{2} . \mathrm{K}\right)$ required after 2020 (2018 for public buildings). Even the best products barely attain this threshold. Figure 2, 3, and 4 show the potential values of heat transfer coefficients on the basis of combinations of frames and panes determined by their heat transfer coefficients. The analysis is based on a $1200 \times 1500 \mathrm{~mm}$ window (the minimum area for which the heat transfer coefficient value is mandatory), with a frame width of $80 \mathrm{~mm}$. Figure 2 is modelled for a linear loss coefficient of glass of $\Psi_{\mathrm{g}}=0.08$ $\mathrm{W} /(\mathrm{m} . \mathrm{K})$. Figure 3 is modelled for a linear loss coefficient of glass of $\Psi_{\mathrm{g}}=0.06 \mathrm{~W} /(\mathrm{m} . \mathrm{K})$. Figure 4 is modelled for a linear loss coefficient of glass of $\Psi_{\mathrm{g}}=0.04 \mathrm{~W} /(\mathrm{m} . \mathrm{K})$.

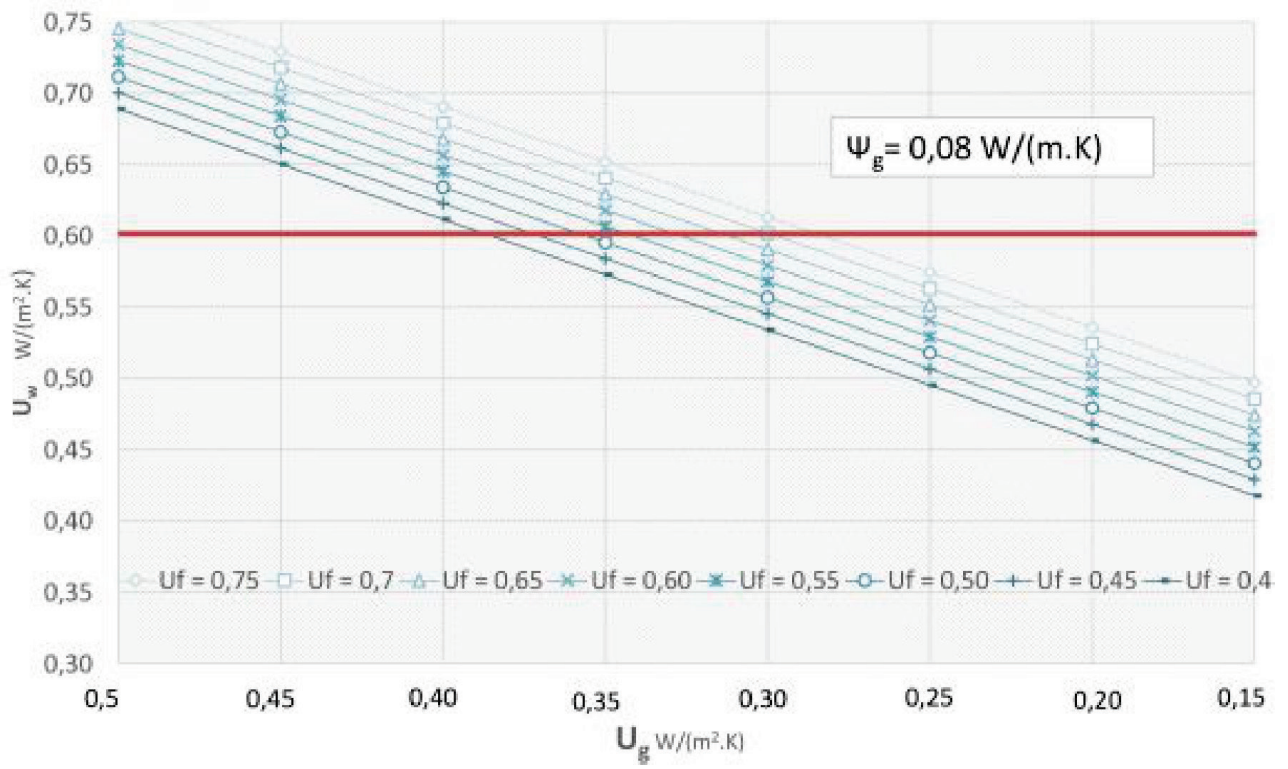

Fig. 2. Potential heat transfer coefficient of window for $\Psi_{g}=0.08 \mathrm{~W} /(\mathrm{m} . \mathrm{K})$. 


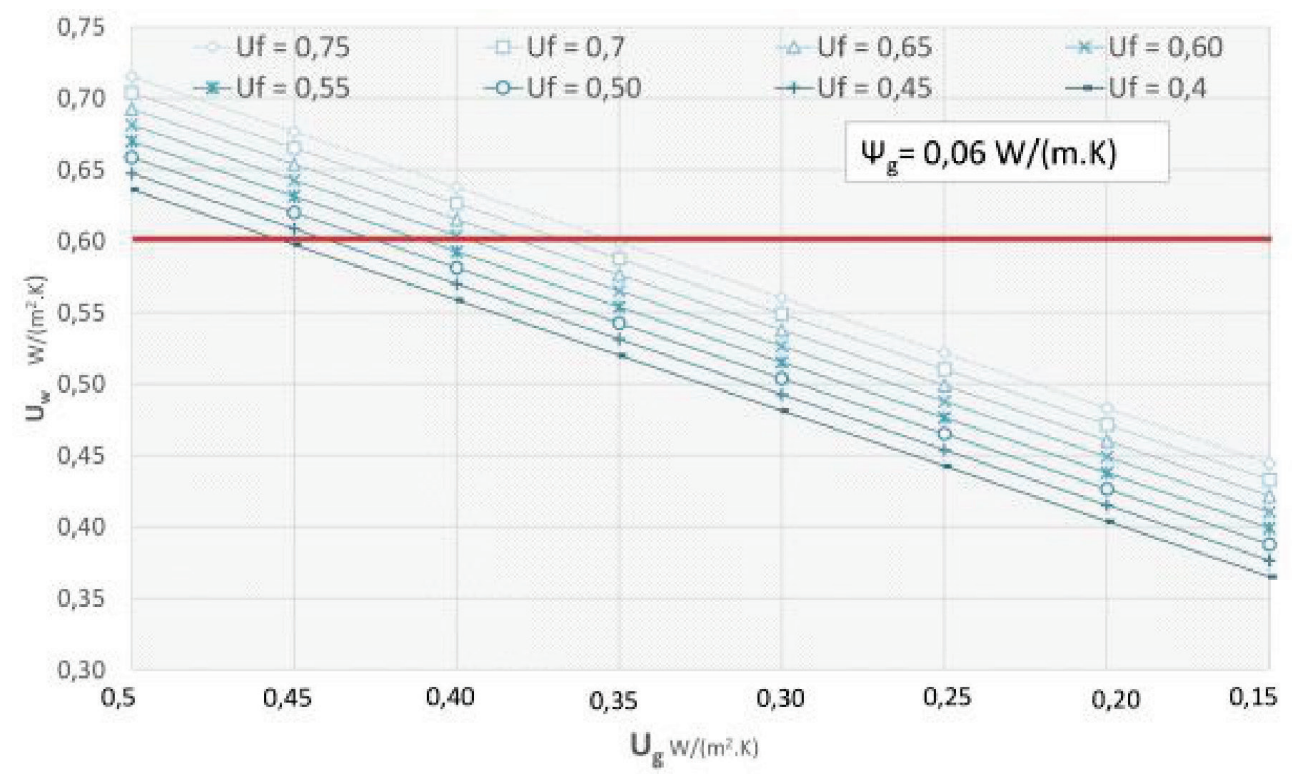

Fig. 3. Potential heat transfer coefficient of window for $\Psi_{g}=0.06 \mathrm{~W} /(\mathrm{m} . \mathrm{K})$.

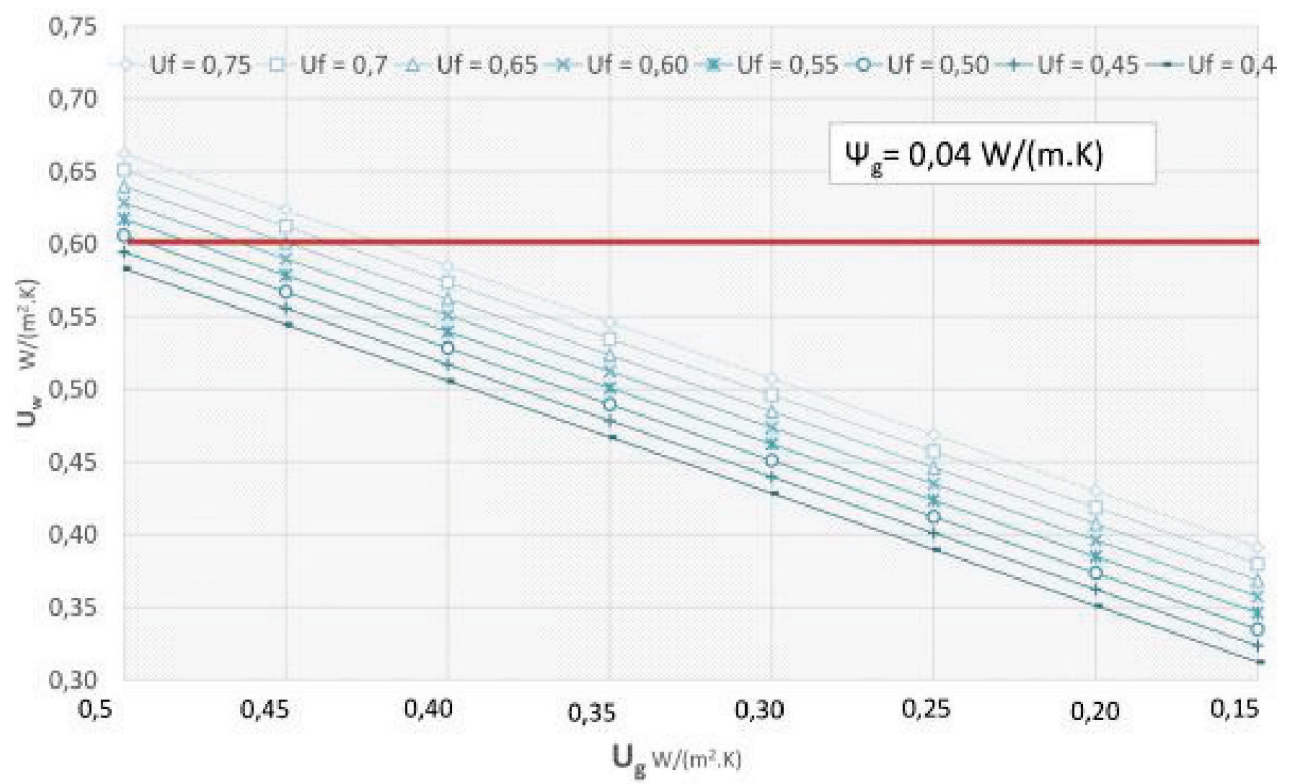

Fig. 4. Potential heat transfer coefficient of window for $\Psi_{g}=0.04 \mathrm{~W} /(\mathrm{m} . \mathrm{K})$.

\section{Problems related to modern windows}

With the production of high quality window constructions, there are problems that have not occurred during the previous lower physical quantification of the windows. Ambient environments through indoor and outdoor climate affect the window structure. Trends in lowering the energy demands of a building lead to physical processes that have not been so far in the past. Infiltration through the window structure is eliminated and forced ventilation 
often causes exfiltration. These changes in physical modes cause condensation or icing in the functional window of the window and thus the risk of mold formation.

In practice, more and more the question arise, "Why are windows misted on the outside?" among the house owners with high quality glass systems. The problem of outer condensation occurs considerably towards the end of summer and early autumn.
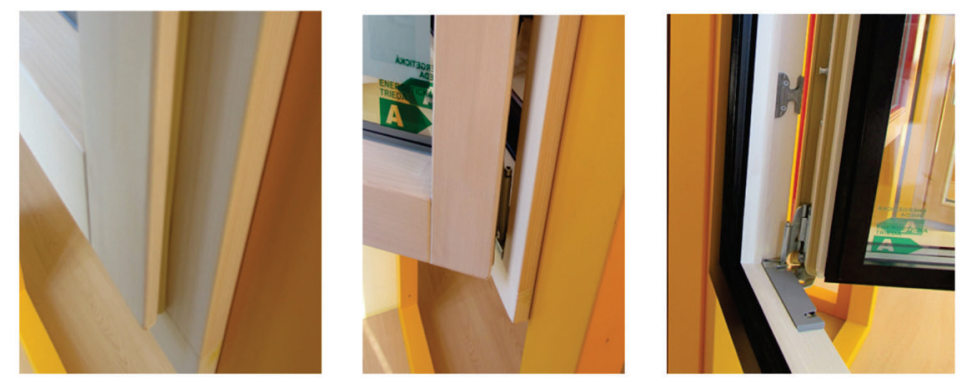

Fig. 5. Hidden all-round fittings.

\subsection{Condensation of water vapor on external glazing}

Surface condensation of water vapour appears on the external surface of an insulating glazing, if the temperature at the surface of the glazing is substantially lower than the air temperature and if it drops below the dew point. The surface temperature at the outside of the glazing is dependent on:

- heat flow from the inside out,

- transfer of heat by convection with the outside air,

- heat loss by radiation (especially sky component).

Efficient thermal insulation glazing leaks only little heat from the inside out. As a result, the outer pane of the glazing remains relatively cold and therefore leads to a formation of condensation. This is due to the temperature difference between the air and the window area. With the increasing temperature the air can hold more water resulting in a higher relative humidity of the air. If the morning air is warming faster than the window glass, the glass surface is colder compared to the temperature of the air, and the water vapour condensates even in case of quality thermal insulation glazing. Skylights are more affected because they are cooled faster than vertical glazing. Given the above, the increasing of thermo-technical quantification of filling of holes in the outer wall leads to the emergence of new problems related to the hygienic quality of the internal environment or visual discomfort (fogging), and others [7].

Figure 6 shows exterior condensation and frost. Thermal triple glazing in a singlefamily house is shown on the left. On extremely cold days, frost can develop on the exterior surface. The right side shows the early phases of testing of vacuum-insulated glazing in the laboratory at the Faculty of Civil Engineering at Slovak Technical University. The image shows water vapour condensation on vacuum-insulated glazing from the cold chamber side. The thermal bridges created by the spacers between the panes form an interesting effect on the vacuum-insulated glazing. 

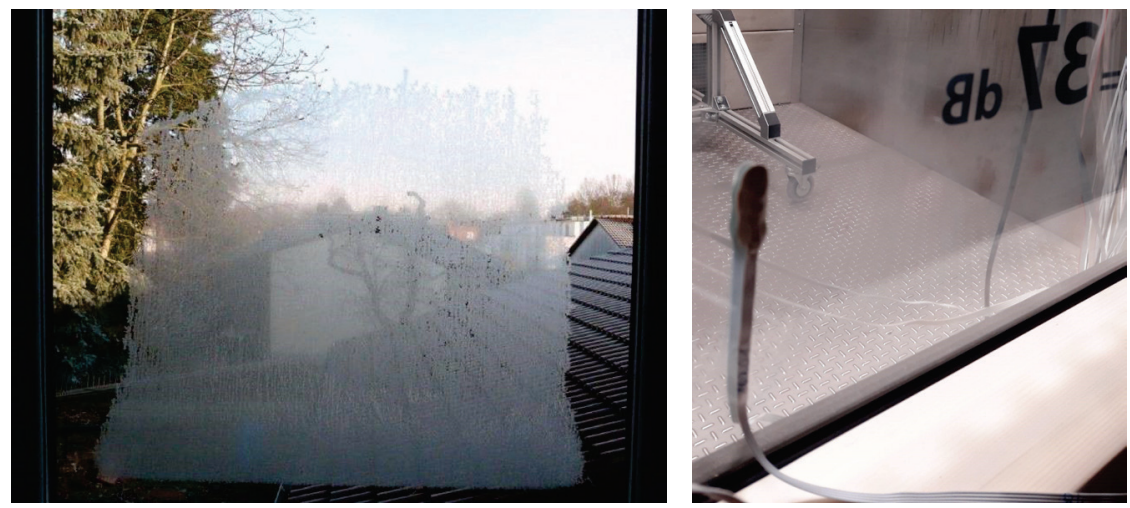

Fig. 6. The formation of condensation and icing from the outside of a quality glass system

\subsection{Condensation of water vapor in a functional gap}

The moisture transport through gap between casement and window frame at condensation temperature is the main cause of condensation of water vapour.

- Air pressure differences (taking water vapour) - infiltration a exfiltration,

- Diffusion of water vapour (different saturation of water vapour in exterior and indoor air). Condensation of water vapour - phenomena for balancing water vapour partial pressure by interaction of molecules. The diffusing water vapours are moving from places having higher pressure to places with lower pressure [8].
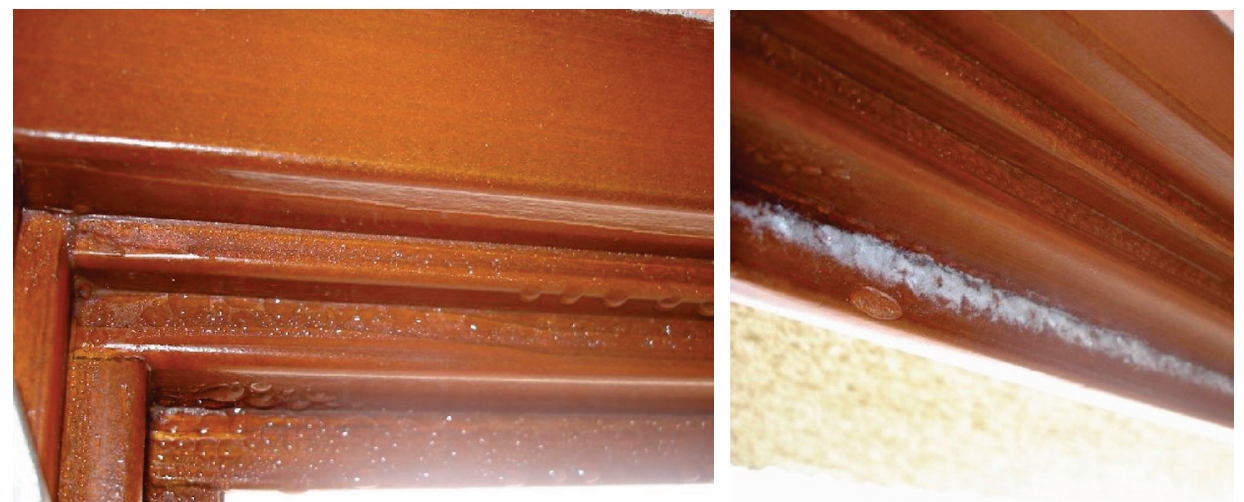

Fig. 7. Condensation and frost of water vapor in a functional gap

Figure 4 shows condensation and frost in the functional gap between window and wood frame. Long-term exposure can damage the surface treatment and as a result, moisture permeates the wood and causes rot. Mould can form in the case of passive windows on buildings where the windows are infrequently opened. Mould is a human carcinogen and creates an unsuitable environment for allergy sufferers and asthmatics. The condensation of water vapor in the joint will improve the acoustic properties slightly $[9,10]$.

\section{Conclusions}

The profile solutions and pane systems regularly available on the market cannot achieve the value of $U_{w} \leq 0.6 \mathrm{~W} /\left(\mathrm{m}^{2} . \mathrm{K}\right)$ required after 2020 (2018 for public buildings).In the coming years, manufacturers of profiles, panes, and particularly manufacturers of windows will be 
faced with the challenge of implementing the new standards. We can expect the introduction of new types of panes and frames. This new added value may also bring with it higher window prices. One possible benefit is that after the new types of windows are installed in buildings constructed after 2020, it is highly likely that we will no longer experience the problems in the interior of buildings that today are frequently attributed to new windows and replacement windows.

This research was supported by Scientific Grant Agency MŠVVŠ SR and SAV under VEGA 1/0685/16. This research was also supported by Apol, s.r.o.

\section{References}

1. STN 73 0540-2 Thermal protection of buildings. Thermal performance of buildings and components. Part 2: Functional requirements (2012)

2. STN 73 0540-2/Z1 Thermal protection of buildings. Thermal performance of buildings and components. Part 2: Functional requirements, Change 1 (2016)

3. P. Oravec, Procedia Manufacturing 2, 348-352 (2015)

4. P. Oravec, AMR 899, 184-187 (2014)

5. M. Bagoňa, Thermal protection of Building 13(1) (2010)

6. Izolačný systém na báze vákua. Available on http://www.asb.sk/stavebnictvo/konstrukcie-a-prvky/okna-dvere/systemy-zaskleniazhladiska-tepelnej-ochrany-budovy

7. A. Palková, M. Palko, AMR 820, 293-298 (2016)

8. M. Palko, A. Palková, Proceedings of 24th SVSFEM ANSYS Users' Group Meeting and Conference 2016, 77-84 (2016)

9. D. Dlhý, K. Minarovičová, AMR 899, 487-490 (2014)

10. D. Dlhý, ATF 2013: 2nd Conference on Acoustics, Light and Thermal Physics in Architecture and Building Structures.Book of proceedings. 21-24 (2013) 